\title{
Theories of social constructivism in Anglophone historical epistemology in 2000-2015
}

\author{
Vera Ageeva ${ }^{1, a}$ \\ ${ }^{1}$ National Research Tomsk Polytechnic University, Lenin Avenue 30, Tomsk 634050, Russia
}

\begin{abstract}
Social constructionism can be seen as a source of the postmodern movement, and has been influential in the field of cultural studies. The article is devoted to the analysis of the influence of social constructionism in modern Anglophone historiography and historical epistemology (2000-2015). The research results show the meaning and place of social and cultural constructivism in contemporary AngloAmerican theoretical historical reflection. Nowadays constructivism is the theoretical framework for many quantitative researches in history. The authors have discussed constructivism and post-constructivism as "umbrella-approaches" and not as "fully-fledged theories" in modern Anglophone historiography. The presence of theoretical foundations of social constructivism in contemporary Anglophone historiography, its role and level of influence can be accurately described as a "critical inoculation constructivism". To this day the theories of social constructivism perform many reflective and critical functions in cultural history and contemporary Anglo-American historiography. The ideas and postulates of social constructivism continue to play a prominent role in the "democratization" of modern socio-humanitarian knowledge, rethinking ethnicity, gender, socio-cultural identity. The theories of social constructivism are actively used in such historical projects and research directions as gender history, feminism history, sport history, the history of popular culture, media communications, and many others.
\end{abstract}

\section{Introduction}

Social constructionism can be seen as a source of the postmodern movement, and has been influential in the field of cultural studies. In the modern historiography, there is a radical opinion on social constructivism, also known as "social constructionism", according to which an anti-realist, relativist stance is essential. Of course, social constructivism is a very broad and poorly internally integrated direction of modern humanities research.

The theories of social constructivism integrate with reference to the processes of reality constructing. In general terms, social constructs commonly mean methods of the world interpretation that people create for the prediction and interpretation of events.

By means of "social constructs", society, social groups and individuals perceive the world and assess the situation. The theories of social constructivism are based on the idea that knowledge is not the reflection and representation, but an active construction of the image of knowable objects and events in the subject's consciousness. The development of constructivist theories occurred in the field of such sciences as psychology, pedagogy, sociology, anthropology, linguistics.

\footnotetext{
${ }^{\mathrm{a}}$ Corresponding author: iforya@yandex.ru
}

Social constructivism has earned the highest authority in such areas of special historical research, where factual knowledge suffers from insufficient and unreliable primary historical sources, first of all, in the ancient and medieval history. For this historical knowledge it is important that people construct the world being not alone in their mind, but together - in the course of conversations and social practices, by mutual agreement. This thesis allows considering the behaviour of social groups in relation to the history and culture of particular communities, recognizing that the historical ways of interpreting the world are diverse and different from current ones.

Modern cultural anthropology and politanthropology take into account that construction of reality is created according to certain implicit rules, escaped the attention of "designers" themselves. Existing mechanisms used for "worlds constructing" are largely "mandatory" for subjects (actors), which are determined by numerous socio-historical and cultural factors, as well as human cognitive abilities.

Numerous theories of social constructivism use different terminology related to the different scientific traditions and have different disciplinary affiliation. However, social constructionism has a social rather than an individual focus $[1,2]$. 
The idea of an active role of the individual and collective consciousness in the process of "world view" creation eventually projected on the reality itself. Daily practical activity leads to the "construction" or "invention" of the "realities", which acquire independent existence, but retain the genetic connection with their creators - social actors [3].

While constructivist epistemology wins today, the location of the growing number of Russian scientists from a variety of social sciences, the influence of social constructionism are not so extensive in the sphere of Western socio-humanities. Nowadays constructivism is the theoretical framework for many quantitative researches in history.

The authors have discussed constructivism and postconstructivism as "umbrella-approaches" and not as "fully-fledged theories" in modern Anglophone historiography $[4,5]$. In spite of the growing interest of Russian social sciences and humanities to the theories of social constructivism $[3,6,7]$, they do not belong to the mainstream of contemporary Anglo-American historical epistemology and social sciences in general $[8,9]$.

\section{Materials and methods}

The article is devoted to the analysis of the influence of social constructionism in modern Anglophone historiography and historical epistemology (2000-2015). The authors attempt to define the meaning and a place of social and cultural constructivism in contemporary Anglo-American theoretical historical reflection.

Along with the general scientific principles of the system and historicism, the authors rely on traditional tools of historical science - historical-genetic, comparative, typological, problem-chronological methods. This article is based on the representative corpus of Russian and Anglophone historiographical sources published in the 21 th century.

\section{Social constructivism for the ancient and medieval history}

The significant example of constructivism implementation in ancient and medieval historical studying is ethnological constructivism. The formation of the postmodern paradigm and methodological development of the ideas of social constructivism led to a "constructivist approach" to the analysis of ethnos and ethnicity in works of E. Gellner, B. Anderson, F. Bart, H. Wolfram $[10,11]$.

In western humanities of the beginning of the $21 \mathrm{st}$ century, there has been an established idea that the ethnicity is a social construct, the result of active creative interpretations of reality by people. Such "objective indicators" of ethnicity as a language, external physical traits, cultural and mental features or religion are nothing more than a raw material for such interpretations. The same "objective data" often take on different meanings depending on the situation and current interests of an individual or a group.
Ethnological constructivism followed so that to solve several historiographical problems. One of the fundamental ideas of constructivism is that modern nations are not directly related to the ethnic groups existed in the pre-industrial era. Therefore, statements like "French History of the Early Middle Ages" are the modernization of the past. Stressing that inappropriate use of modern notions of ethnicity in relation to distant antiquity, western researchers have made a conceptual change in the understanding of the problem of early medieval xenocraties and the significance of xenocratic elements for the development of authorities and states in the early Middle Ages.

The attention of European national historiography has repeatedly drawn the fact, that in the vast majority of ancient and medieval legends associated with the birth of government institutions, there are the descriptions of alien or foreign origin of rulers. However, the first attempt to decipher the nature of the "overseas" state as a natural phenomenon of the early medieval social development was taken just under the constructivist methodology.

The American sociologist Ernest Gellner in his famous work "Nations and Nationalism" has denied the existence of "national points" in the early Middle Ages. Noting the agricultural and autarkic nature of early medieval societies, the researcher came to the conclusion that all these societies "opposed to bringing political borders in line with the cultural ones", and "no one is interested in the preservation of cultural unity at a social level" [10].

As a rule, the elite retained their power positions, if they successfully perform the essential functions of the state (the war, the court, the collection of taxes). Primitive origin of these functions in the early medieval societies, as well as the use of intermediaries from among the local nobility contributed to the political domination of ethnically foreign element. Thus, a common language and cultural symbols linking the ruling elite and the people, according to E. Gellner, were not historically necessary.

Constructivists argued the position that the ethnicity was not the main criterion of association in social groups in the early Middle Ages, Due to this, the issue of early medieval xenocracy acquired a new research perspective. For example, an Austrian historian $\mathrm{H}$. Wolfram uses the term "gens" in relation to the early medieval communities. This term does not have the conventional English equivalent and only partially coincides with the traditional historiographical concept of a "tribe" [11].

According to the researcher, early medieval primary historical sources indicate fundamental polyethnicity of "gens" which formed the unity of the "people" and "the troops". Gens were not completely fully fledged nations, they never included all possible members of a clan. Gens have always been mixed social groups.

Such communities arose not on the principle of blood kinship. It was a union of diverse groups that made up the barbarian army. A common language, as a rule, was not a criterion for membership of gens: Barbarians spoke different languages, using them alternately. 
Someone became a member of the gens, who considered herself/himself relating to this community by birth, according to the legend, or as a result of the test. Under their development, gens were always "on the road", easily moving and taking a variety of sizes. Amazing social mobility dominated in these communities: the one, who was clever and who was successful in the war, participated in the campaigns of the gens, regardless of ethnic or social origin.

The chiefs and representatives of known families, "leading their descent from the gods" and being able to prove the success of their charisma, formed "traditional centers of gravity" around which there appeared new gens. Owing to to such leaders, according to $\mathrm{H}$. Wolfram, ethnic communities have changed their composition, fragmented or, on the contrary, increased [11]. The development of the gens led to the emergence of barbarian state structures, in which the value of the ethnic aspect of power was minimal for these reasons.

Postmodern methodology of the analysis of ethnic and national communities is a leader in the modern Western humanitarian thinking [12-14]; however, it is not widespread in Russia. To date, the majority of Russian ethnologists and historians remain in positions of social and historical primordialism, i.e. recognition of the natural objective grounds of ethnicity [15].

There is still controversial and debatable a so-called "Norman problem" in modern Russian historiography. A number of current researches actualized the issue about the ethnicity (Scandinavian or Slavic) of the founders of the ancient Russian princely dynasty and the Varangians. However, in recent years the idea of Ethnological constructivism has been reflected in one way or another in the Russian historical science and ethnology.

\section{Social constructivism "for the minorities"}

Social constructivism as a methodology of historical research recognizes the primary role of discourse and relations between people in the construction of the world and their own "I". Application of this methodology leads to the rejection of the ideas of the absolute truth, the standards and patterns of behavior and universal psychological processes.

Researchers consider psychological phenomena (in the historical past and social present) in relation to the culture and history of particular communities. In historical narratives social constructivism seeks to demonstrate this diversity and mutual enrichment of different discourses (languages and ways of interpreting the world).

Today in historical studies there is a confirmation of the idea that belonging to any "minority" is constructed through language in relationships with other people [1618]. Various "designs of the world" are closely associated with inter-consent of what exists and what is valuable in various communities (ethnic, professional, scientific, religious).

Ideas of social constructivism were in the basis of the development of so called "qualitative research".
Researchers seek to identify the historical roots of different forms of reality understanding, exploring the range of variability of human representations in different cultures. Historians actively investigate "conventional social reality", guiding the behaviour of social groups and forming the identity of people.

A statement that gender, sexual orientation, crime and delinquency, employment, accommodation and the provision of goods, religious belief are socially constructed means that this phenomena, as currently understood, are not an inevitable result of biology or individual social activity, but are highly contingent on social and historical processes [19-21].

English and American researches tried to analyse historical "emotionology and aesthesiology". The methodology of social constructivism is considered as very useful in the study of emotional experience in history and when understanding "how emotions mediate between the individual and the social" [22]. Interpretations of sense perception, feelings and emotions as social constructs help to understand power relations in historical societies.

\section{Social constructions and post- constructivism for the history of the 20th century}

The theories of social constructivism are actively used by historians-"practitioners" in such historical projects and research directions as gender history, feminism history, sport history, the history of popular culture, media communications, and many others [23-26]. In many works the authors stress "social constructedness" of the science and any kind of historical knowledge.

A significant number of projects in the history of sport use the tools of social constructivism. D. Booth summarized the research results in the sport history, carried out in 1990 - 2000, analyzed theoretical foundations and methodological approaches which were used in these studies [27].

In a large Booth's study, the boundaries of the application of the positivist methodology and the traditional arsenal of historical methods are shown, and at the same time the major achievements in the history of the sport are illustrated.

These results were received due to the ideas of postmodernism, in particular the methodology of social constructivism. D. Booth examines the politicization of the official documents of the sport history, photos, audio and video archive materials. In the view of the historian there are the political context of social memory, Olympic events, sports achievements, ownership of these achievements in the social memory, sport symbols, sport propaganda and ideology.

By the example of the work of sport historians with different kinds of historical sources, the author demonstrates the difference between the results and rises to the position of social constructivism, since it allows expanding the scope of the study, setting a research context, inscribing the history of sport in the history of socio-cultural, political transformations. 
In the analysis the author works with such constructs as prestige, prestigious costs and prestigious consumption. D. Booth considers the sport on a par with other unproductive expenditures of the state and individuals (luxury, war, cults, games, spectacles, arts).

\section{Conclusion}

In spite of the growing interest of Russian social sciences and humanities to the theories of social constructivism, they do not belong to the mainstream of contemporary Anglo-American historical epistemology and social sciences in general. The presence of theoretical foundations of social constructivism in contemporary Anglophone historiography, its role and level of influence can be accurately described as a "critical inoculation constructivism".

Criticism of social constructivism in theoretical historiography was taken into account and integrated into other approaches by providing historical works on remarks about "the language, culture and actors".

To this day the theories of social constructivism do much reflective and critical functions in cultural history and contemporary Anglo-American historiography. The ideas and postulates of social constructivism continue to play a prominent role in the "democratization" of modern socio-humanitarian knowledge, rethinking ethnicity, gender, socio-cultural identity, as well as any other determination of individuals and social groups.

The theories of social constructivism are actively used in such historical projects and research directions as gender history, feminism history, sport history, the history of popular culture, media communications, and many others.

\section{Acknowledgments}

The present work was supported by the Russian Humanitarian Scientific Foundation, in the framework of the project "Modern historical epistemology and research paradigms of Western historiography in 20002015" (No. 15-01-00427 a).

The research reported in this article was supported by the Strategic Programme on the National Research Tomsk Polytechnic University Competitiveness Enhancement in the Group of Top Level World Research and Academic Institutions.

\section{References}

1. P.L. Berger, T. Luckmann, The social construction of reality: a treatise in the sociology of knowledge (London, 1966)

2. V. Burr, Social Constructionism. (Routledge, 2003)

3. A.M. Ulanovsky, Issues of psychology, 2, 35-45 (2009)

4. A. Whittle, A. Spicer, Organization Studies, 29, 611 (2008)

5. D. Elder-Vass, The Reality of Social Construction (Cambridge University Press, 2012)
6. I.A. Ageev, V.V. Ageeva, Procedia - Social and Behavioral Sciences, 166, 24-29 (2015)

7. N.V. Trubnikova, Procedia - Social and Behavioral Sciences, 166, 666-669 (2015)

8. J. Law, After Method: Mess in Social Science Research (London, 2004)

9. I. Hacking, The social construction of what? (Cambridge, 1999)

10. E. Gellner, Theory and Society, 10(6), 753-776 (1981)

11. H. Wolfram, Die Goten (C.H.Beck, 1990)

12. M. Wilson, K. Bashir, Social Identities, 1-16 (2016).

13. B. Wiener, The Journal of sociology and social anthropology, VIII, 3, 114-130 (2005)

14. J. Gottshcall, D.S. Wilson, (Eds.) The Literary Animal: Evolution and the Nature of Narrative (Evanston, 2005)

15. O.N. Bushmakina, The Herald of Udmurt University, 2, 109-118 (2005)

16. A. Lock, T. Strong, Social Constructionism: Sources and Stirrings in Theory and Practice (Cambridge University Press, 2010)

17. H. Blazsin, F. Guldenmund, Safety Science, (Part A), 16-27 (2015)

18. F.J. Hibberd, Unfolding Social Constructionism (New York, 2005)

19. C.S. Fitzgerald, Journal of Human Behavior in the Social Environment, 21(3), 297-311 (2011)

20. K. Honkanen, European Journal of Women's Studies, 12(3), 281-295 (2005)

21. J.D. DeLamater, J.S. Hyde, Journal of Sex Research, 35(1), 10-18 (1998)

22. J. Bourke, History workshop journal, 55(1), 111 (2003)

23. K. Asdal, History and Theory, 42(4), 60-74 (2003)

24. N. Lykke, Nordic Journal of Feminist and Gender Research, 18(2), 131-136 (2010)

25. P. Somerville, Housing, Theory and Society, 19(2), 78-79 (2002)

26. J.S. Efran, Sh. McNamee, B. Warren, J.D. Raskin, Journal of Constructivist Psychology, 27(1), 1-13 (2014)

27. D. Booth, Rethinking History, 9(4), 459-483 (2005) 